\title{
COMPLEMENTARY ASSETS AND VALUE CREATION BEYOND INFORMATION TECHNOLOGY INVESTMENTS
}

\author{
Godfred Yaw Koi-Akrofi \\ Department of IT Studies, University of Professional Studies, Accra
}

\begin{abstract}
This work was aimed at analyzing the relationships between some selected complementary assets (independent variables) and some specified benefits/value creation (dependent variables), beyond Information Technology (IT) investments in an organizational setting. The purpose was to determine significant complementary assets that impact greatly on value creation beyond IT investments. With 175 questionnaires sent to IT project and program managers of companies in the Telecom industry in Ghana, and analyzed,thefollowing findings were revealed: for value creation beyond IT investments to be achieved, the staff must be computer literate, there must be the availability of experts and firms around to help in resolving IT problems quickly and timely that crop up, and the staff must be empowered to be innovative with IT. Again, the results showed that most of the complementary assets employed in this work, tend to favor benefits of Improved staff morale and Improved business processes. Also, one of the strongest positive relationships was found to exist between "supportive organizational culture that values efficiency and effectiveness" as predictor variable and "service/product quality" as response variable.
\end{abstract}

\section{KEYWORDS}

Complementary assets, information technology, value creation, investments, intangible and tangible assets

\section{INTRODUCTION}

The relationship between information technology (IT) investment and value creation in organizations has been an important topic in MIS research for years. LinA, Bou-Wen [1] noted that information technology (IT) has become an unavoidable, essential component of firm capacity and something from which to gain a sustainable competitive advantage. LinA[1] continued to determine that the empirical results of the relationship between IT capability and firm performance are still equivocal, regardless of the above statement. This confusion is due to research results that are inconsistent or conflicting, and this has contributed to the ambiguity in justifying IT spending by IT managers.

Studies on the relationships between IT investment and organizational performance and productivity (or value creation) revealed, in some cases, positive and notable effects of such investment (Barua, Kriebel, \& Mulhopadhyay [2]; Brynjolfsson \& Hitt [3]; Kaplan, Krishnanm, Padman, \& Peters [4]; Lehr \& Lichtenberg [5]; Mahmood \& Mann [6]; Rai, Patnayakuni, \& Patnayakuni [7]), while in other cases, studies have revealed no noteworthy relationship (Berndt \& Morrison [8]; Koski [9]; Strassman [10]; Strassman [11]). Some reasons have been given for these contradictory results; some researchers attribute it to inadequate data and flawed methodology (Brynjolfsson [12]; Sircar, Turnbow, \&Bordoloi [13]). YiHua and Mykytyn [14] 
also giving their view on the same subject mentioned that handling IT investment as a black box without looking further at what is going on inside the box could be an even bigger cause. It is based on this that researchers like Koi-Akrofi and Koi-Akrofi [15] tried to expand the discussion to cover the pre-IT investment activities, the IT investment itself, the conversion effectiveness, and the gap between the investments and the yields of the investments. It was revealed that all these factors mentioned contribute immensely to value creation. Conversion effectiveness has the following components: top management commitment, previous firm experience with IT, user satisfaction with IT systems and tools, Power and politics of the firm, and culture of the firm regarding IT [15]. These factors, they maintained that when emphasized positively can result in IT investments producing fantastic gains. Several of the aforementioned items constitute what we call complementary assets.

Teece [16] defined complementary assets as those assets required to derive value from a primary investment (as cited in Laudon and Laudon [17]). It is worth noting that some work has already been done in the area of complementary assets aiding IT investments to create significant values, however, quite old; Researchers (Brynjolfsson [18]; Brynjolfsson \& Hitt [19]; Davern \& Kauffman [20]; Laudon [21]) revealed that firms that support their technology investments with investments in complementary assets, such as new business models, new business processes, management behavior, organizational culture, or training, receive greater returns, whereas those firms failing to make these complementary investments receive less or no returns on their information technology investments. This work takes a different approach by answering the question "what benefit/value is created from which complementary asset?" The general objective of the study, therefore, was to contribute to the general body of knowledge and research work in complementary assets and value creation beyond information technology investments. To achieve this objective, the research was targeted at analyzing the relationships between specific complementary assets and selected benefits (Increased Revenue, enhanced competitive advantage, improved staff morale, improved decision making, improved business processes, and improved product/service quality) of IT investments.

\subsection{The Research Problem}

Indisputably, IT has and continues to play a major role in the operations of businesses all over the world to achieve expected outputs/results or goals. This undisputed fact, though difficult to ascertain theoretically, is what has been pushing managers of businesses to continue to invest in IT. Ahmad and Arshad [22] revealed that huge IT investments are made in organizations worldwide due to the notion or belief that these investments produce productivity and values/benefits which may be intangible. Theoretically, researchers have tried over the years to quantify or determine the benefits of IT investments in terms of productivity and profitability. In achieving this, many frameworks, models, and approaches have been employed by researchers over the years.

The main approaches are to determine performance from a direct investment in IT or performance from IT investments through mediating factors (organizational capabilities) (Liang, T-P., You, J-J., \& Liu, C-C. [23]; Dehning, B., \& Richardson, V. J. [24]). In the former approach, results have not been straightforward, evidenced by the productivity paradox (opposing views or positions of researchers on productivity when it comes to value creation after IT investments), and opposing profitability outcomes. To ensure benefits realization (tangible and intangible) beyond IT investments, some researchers [18-21] have suggested investments in complementary assets, for which they argue that value creation is only achieved when commensurable investments are made in complementary assets alongside the Information Technology investments. This is in line with the later approach of performance from IT investments through mediating factors (organizational capabilities) which has been proven to yield results $[23,24]$. 
This study intends to analyze the relationships between complementary assets as was proposed by Laudon and Laudon [17], as independent variables and some specified benefits (tangible and intangible) as was proposed by Ahmad and Arshad [22], as dependent variables, to establish significant variables within a framework for value creation beyond IT investments.

\section{LiterATURE REVIEW}

\subsection{Complementary Assets}

IT investments alone cannot make organizations and managers achieve fantastic results in terms of profitability and productivity unless they are accompanied by supportive values, structures, and behavior patterns in the organization and other complementary assets [17]. Laudon and Laudon [17] continued to say that before business firms can reap the advantages of new information technologies, they need to change how they do business; some firms fail/refuse to adopt the right business model that suits the new technology or seek to maintain an old business model that is driven by new technology.

Complementary assets are those assets required to derive value from a primary investment [25]. In this instance, IT investment is a primary investment. Research on business information technology investment shows that firms that support their technology investments with investments in complementary assets, such as new business models, new business processes, management behavior, organizational culture, or training, obtain receive splendid/superb returns, while those firms failing to make these complementary investments receive less or no returns on their information technology investments $[18,20,21,26]$

In explaining the significance of this concept, this question can be asked: what is the essence or benefit of investing so much in computers in an organization, without training the staff how to use a computer? The net effect will be that the intended benefit that motivated the investment in the first place will never be achieved. This is because the staff will not use it. The investment will become a "white elephant". This is the concept behind complementary assets. They are complementary because we see them as helping the IT investments to achieve what they are intended to achieve.

According to Laudon and Laudon [17], Complementary assets are grouped into three aspects:

- Organizational investments: This has to do with the following:

- Supportive organizational culture that values efficiency and effectiveness

- Appropriate business model

- Efficient business processes

- Decentralized authority

- Distributed decision-making rights

○ Strong IS development team

- Managerial Investments: This has to do with the following:

- Strong senior management support for technology investment and change

- Incentives for management innovation

- Teamwork and collaborative work environments

- Training programs to enhance management decision skills

- Management culture that values flexibility and knowledge-based decision making.

- Social Investments: This has to do with the following:

- The Internet and telecommunications infrastructure

- IT-enriched educational programs raising labor force computer literacy 
- Standards (both government and private sector)

- Laws and regulations creating fair, stable market environments

- Technology and service firms in adjacent markets to assist implementation

Investing in the above alongside IT will yield good returns as against investing in IT alone. This is the whole concept of complementary assets and IT investments in creating organizational value. This whole concept of complementary assets investments alongside IT investments came because of the productivity paradox which has been a standing issue in literature. The current research drive is towards maximizing value creation from IT investments using complementary assets.

Examples of the application of this concept in organizations are as follows:

- Investing heavily in IT infrastructure and training the users as well. The two activities should be done at the same time so that the systems will not wait for the people to be ready. Immediately the systems are ready, the users should also be ready to use them for value realization.

- Investing heavily in local area networks and enterprise systems and not giving internet access to staff. For the systems to be used effectively, the staff need internet access.

- Investing heavily in IT without business processes in place. This will mean that though what is needed to ensure that the processes work is in place, the processes themselves are not in place. This allows or permits the wrong use of the IT systems.

- Investing heavily in IT without IT policy in place. Staff will use the systems anyhow, posing security concerns, and so on, and that will not bring productivity to the business

Organizations make a big mistake in investing so much in IT and forget all other things that are closely related to the investment. Universities spend so much money to buy and install MIS systems for the registry, students, and faculty for academic work, but they find it difficult to invest money in the training of administrative and faculty staff to enable them to use the system efficiently. At the end of the day, they do not use it, and in most cases return to the manual way of doing things. This problem persists in almost all institutions. Complementary assets investment is key to realizing the full benefits of IT investments.

\section{Materials ANd Methods}

\subsection{Introduction}

This portion documents the research design and methods, research format, Techniques/Tools/Approaches/Instrumentation/Devices, data collection methods, and Population and Sampling Procedures. This chapter specifically answers the "how?" and "why?" these methods, procedures, techniques, and formats are employed. It also describes the proposed solution strategy/approach or method and expected results.

The main issue at stake for this research work can be summarized into one research question: do complementary assets contribute positively to value creation in organizations beyond IT investments? This work uses the methods, procedures, techniques, and formats it employs to analyze the relationships between complementary assets and benefits beyond IT investments. 


\subsection{Research Design and Method}

This research adopts both qualitative and quantitative approaches. The quantitative approach is employed because it involves the systematic empirical investigation of social phenomena via statistical, mathematical, or computational techniques. The objective of quantitative research is to develop and employ mathematical models, theories, and/or hypotheses about phenomena, which forms part of the scope of this work. A qualitative approach is also employed because this work seeks systematic empirical inquiry into meaning [27]. By systematic he meansplanned, ordered, and public, following rules agreed upon by members of the qualitative research community. By empirical, means that this type of inquiry is grounded in the world of experience. Inquiry into meaning says researchers try to understand how others make sense of their experience. Qualitative research seeks out the "why", not the "how" of its topic through the analysis of unstructured information - things like interview transcripts, open-ended survey responses, emails, notes, feedback forms, photos, and videos. It does not just rely on statistics or numbers, which are the domain of quantitative researchers. Qualitative research is used to gain insight into people's attitudes, behaviors, value systems, concerns, motivations, aspirations, culture, or lifestyles; some of which are employed in this study. It is used to inform business decisions, policy formation, communication, and research. Focus groups, in-depth interviews, content analysis, ethnography, evaluation, and semiotics are among the many formal approaches that are used, but qualitative research also involves the analysis of any unstructured material, including customer feedback forms, reports, or media clips.

Apart from the questionnaire administration, IT, few strategic/top, tactical, and operational managers of the organizations concerned wereinterviewedindividually and in groups to give their candid views concerning the subject matter. The information that was gathered from these interviews and discussions formed the basis for the qualitative aspect of the study, that is, the formulation of the conceptual framework and the various parameters/measures which formed the basis for the theoretical framework and subsequently the quantitative analysis.

Quantitatively, the data gathered from the questionnaires are coded into a 5 category Likert scale that is analyzed using statistical models and tests and interpreted. Quantitative studies are used to test hypotheses to support the generalizations from the qualitative study, estimate parameter coefficients, and determine the significance of parameters and models. The theoretical framework derived from the conceptual framework based on inputs from IT managers, top executives, tactical and operational managers of the Telecom industry in Ghana, especially in the area of determination of metrics for the complementary assets, is shown in figure 1 below: 
International Journal of Managing Value and Supply Chains (IJMVSC) Vol. 11, No. 2, June 2020

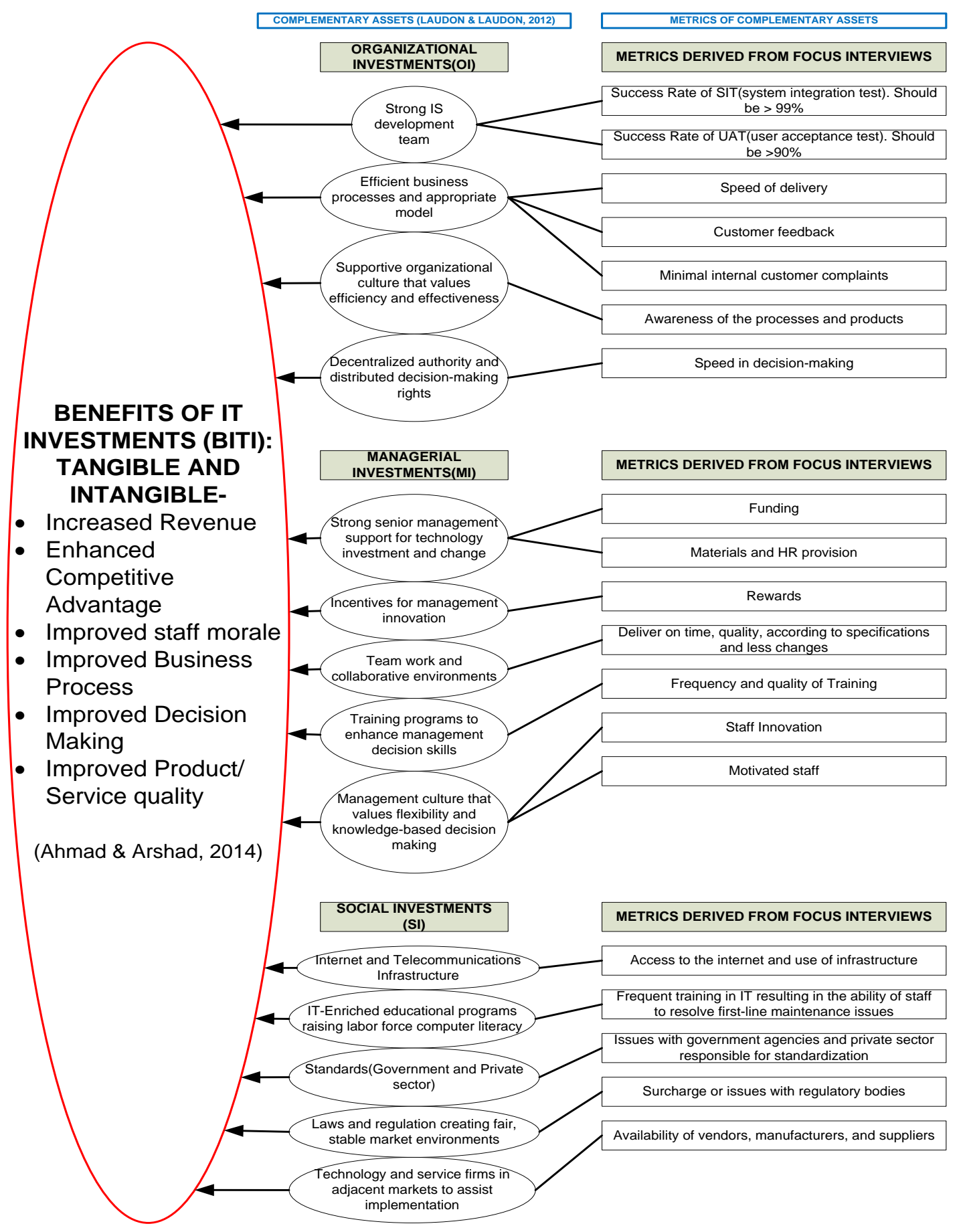

Figure 1: Theoretical Framework

Source: Author

We use the ordinal regression model as employed in SPSS because the data, especially the fact that the data of the dependent variable are of the ordinal type, and the independent variables are also ordinal and categorical, which are considered in SPSS as factors. Continuous independent variables are also considered in SPSS as covariate variables.

The general model is as follows: 
Taking the dependent variable BITI as in figure 1, we have

$\operatorname{Ln}(\Theta j / 1-\Theta j)=ß 0 \mathrm{j}-ß 1 \mathrm{R} 1-\beta 2 \mathrm{R} 2-ß 3 \mathrm{R} 3-\ldots-\beta 14 \mathrm{R} 14 \ldots \ldots \ldots$...eqn. $\mathrm{i}$

The function on the left-hand side of the equation is termed the logit function. $\beta \mathrm{n}$ (where $\mathrm{n}$ is from 1 to 14 ) is the coefficient of an independent variable. Each logit has its $B 0 \mathrm{j}$ term but the same coefficient $B$. That means that the effect of the independent variable is the same for different logit functions.

\subsection{Research Format}

The research format is predominantly exploratory and causal. Exploratory, because experience survey as a method under exploratory was employed. For experience surveys, experienced IT managers, as well as the top, tactical, and operational managers, wereinterviewed individually on the subject matter. This approach considers every experienced person in the company to ensure fair evaluation of issues, rather than only executives who may conceal a lot of information; it is a broad-based approach. An executive survey was employed because the study was interested in primary data only.

Again, it is a causal study because the study was interested in finding relationships as is demonstrated by the model above. Here we are looking at the concomitant variation-the degree to which a presumed cause (e.g. OIDP-Strong Information System development team) and a presumed effect (BITI) occur together or vary together. This is where the hypothesis comes in. If the stated hypothesis was that there is a positive relationship between OIDP and BITI, and it turns out to be false at the end of the day, after hypothesis testing, then the hypothesis is not supported.

\subsection{Techniques/Tools/Approaches/Instrumentation/Devices}

The 5 category Likert scale was used for the questionnaire administration. This is an ordered scale with code 1 representing strongly agree, 2 agree, 3 neutral, 4 disagree, and 5 strongly disagree. This goes for both dependent and independent variables, where applicable. Likert scale data is an ordinal data type that requires non-parametric tests and non-parametric regression methods. The median is also used instead of the mean as a measure of central tendency. There are two schools of thought as to the treatment of Likert scale data. Some researchers $[28,29,30]$ are of the view that Likert scale data is ordinal data, and that using the 5 category scale employed in this study as an example, the difference between consecutive categories, even though is one, and hence satisfying the equidistance condition for an interval scale data type, is still ordinal. They argue that the difference between "agree" and "strongly agree" is not the same as between "strongly disagree" and "disagree", and for that matter, the equidistance property is of no use. To these researchers, only non-parametric tests (chi-squared, Spearman's Rho, or the Mann-Whitney U-test, Kruskal-Wallis test: a non-parametric alternative to ANOVA) and non-parametric regression analysis (ordinal regression, localpolynomial regression, kernel estimation, and smoothing splines) are applicable. To other researchers $[31,32]$ this is not so. They consider Likert scale data as having both ordinal and interval characteristics. They also argue that an assumption of equidistance can be made, especially with the 5 category Likert scale where the middle number 3 represents neutral.

They continue to argue that with a large sample size (over a hundred), and well spread to cover a majority area of the population, with different categories of respondents, the data assumes a normal distribution where all the measures of central tendency (mode, median, and mean) appear to merge at the middle; in other words, skewness assumes that of the Gaussian or normal distribution, and parametric tests such as the Pearson correlation, and ANOVA analysis 
can be employed. Again, they argue that in this instance the mean can be used instead of the median. Another assumption they make is the number of categories of the Likert scale; the higher the number of categories (more than 3 ) for the dependent variable/s, the more outcomes become accurate with the usage of parametric tests and methods.

In this study, the author sides with the view that Likert scale data, especially for dependent variables, have ordinal characteristics, and hence should be analyzed using non-parametric tests and methods. The parametric analysis will therefore not be used for this study. The regression model above has been modeled based on the ordinal regression model which is non-parametric. SPSS (Statistical Package for the Social Sciences) is employed to run the statistics (both descriptive and inferential). A Non-parametric analysis is interested in the following: Spearman rank correlation coefficient, parameter estimates, Strength of Association-Pseudo R Square: Cox and Snell R2, Nagelkerke's R2, McFadden's R2, overall fitting test, and parameter significance. Descriptive statistics such as the mean, standard error, median, mode, standard deviation, sample variance, kurtosis, and skewness are also estimated, even though it is only the median that is used. Inferential statistics are used to test hypotheses stated, that is, to generalize observations made with samples to the larger population from which they were selected. The most significant parameters are then compared for the model to see which one has the greatest impact on the dependent variable. The result is the formulation of a model using these significant parameters. The focus of the study, however,was to determine these significant parameters, and not to find a fitting model per se.

Reliability (the extent to which a questionnaire, test, observation, or any measurement procedure produces the same results on repeated trials) analysis is done to ensure whether the questions in the questionnaire can be relied upon for good analysis or not. This is essential as the outcome of this work was also to find the significant complementary assets that help create value beyond IT investments.

\subsection{Data Collection Methods}

This study used or employed primary data for its analysis. No secondary data was used. All the information was gathered from face-to-face interviews and questionnaire administration. Using the 5 category Likert Scale, several questions were asked for the dependent variables (BITI); 6 in all as shown in the theoretical framework (Figure 1).

For the independent variables (14 in all), they are all considered as categorical (factors). There are no continuous (covariates) variables. The ordinal type of independent variables still follows the 5 category Likert scale where answers/responses to these questions were coded from 1 to 5 , which is from "strongly agree" to "strongly disagree", analyzed in SPSS, and then interpreted.

\subsection{Population and Sampling Procedures}

The service sector in Ghana was used as the population for this study. The service sector includes the following: telecommunications companies, banking and non-banking financial houses, hospitals, utility services, and so on. The telecommunications industry was, however, the only one considered as a case for this study. This industry was chosen from the lot in the service sector because it uses or employs IT more in its operations than the others. IT investments are huge in this industry, and so dealing with them would present an interesting scenario in terms of the data collection, interviews, results/outcomes, and so on. All the telcos have their headquarters in Accra, and most of their operations are in Accra, and so Accra was chosen as the location for the survey. A probability sampling (random sampling) method was employed. 


\subsubsection{Surveys}

Selected IT project managers/ IT managers and IT professionals for the case industry were employed for the face to face and focus interview sessions. The main aim was to target experienced and knowledgeable professionals in the IT space to interview on the subject matter. For the questionnaire administration, one hundred and seventy-five (175) questionnaires were, however, sent to IT managers, IT project managers, IT program managers, and all stakeholders in the IT project space of the targeted industry. The Telecommunications industry in Ghana has 5 active companies namely MTN, VODAFONE, TIGO, AIRTEL, and GLOBACOM. Thirtyfive questionnaires were sent to each of them summing up to one hundred and seventy-five.

\subsubsection{Sample Size Calculation}

An approximate number of sixty-four (64) employees in the IT project space (IT managers, IT professionals, IT project managers, IT program managers, and so on) for one of the Telcos was used as a standard sampling unit for the 5 sampling frame. In effect, the approximate target population was estimated to be $(64 * 5)$ which is three hundred and twenty $(320)$. For a common choice of 5\% margin error, and a standard choice of $95 \%$ confidence level, which gives a $\mathrm{Z}$ score of 1.96, and a sample proportion of 50\% typical of a first time survey, a sample size of one hundred and seventy-five (175) was realized. This was the sample size employed for the study. The formula used for the calculation of the sample size is as follows:

$\mathrm{n}=$

$$
\mathrm{Z}^{2} * \mathrm{P}(1-\mathrm{P})
$$

$$
1+\left(\left(\mathrm{Z}^{2} * \mathrm{P}(1-\mathrm{P})\right) / \mathrm{e}^{2} \mathrm{~N}\right)
$$

Where $\mathrm{N}=\mathrm{POPULATION}=320, \mathrm{Z}$ score $=1.96, \mathrm{P}=$ sample proportion $=50 \%=0.5$, e=error margin $=5 \%=0.05$

\section{RESULTS}

\subsection{Introduction}

The telecommunications industry was used as a case for the study. In Ghana, the major telecommunications companies are MTN, VODAFONE, TIGO, AIRTEL, and GLO. The metrics for the complementary assets were developed during an initial survey engaging 8 IT project and program managers from the 5 Telcos in Ghana. The questionnaire for the thesis work was then developed. The questionnaire consists of 4 parts: personal information, Information about the organization related to IT projects of which the answers are of the dichotomous type (yes or no), IT investment benefits( the dependent variables), and the complementary assets (independent variables).

Thirty-five (35) questionnaires were sent to each of the above Telcos, and the people targeted were IT project stakeholders, especially, IT project and program managers. In all 175 questionnaires were administered, but only 125 were retrieved from all the Telcos; 50 were not retrievable. This was due to the tight schedules of the respondents, among other things. Out of the 125 respondents, 123 people answered the question of the number of years worked in the organization, and the output shows that about $77.2 \%$ of them have worked in their organizations from between $0-9$ years. $13 \%$ have worked between 10-14 years and the minority $9.8 \%$, beyond 14 years. This gives fairly balanced statistics and helps to balance responses on issues, rather than the possibility of a skewed response when all of them were to be in a particular range. For the number of years in a management role, about $94.6 \%$ of them fall between $0-9$ years and the remaining, beyond 10 years. This also shows that all the respondents 
have some managerial experience. This is good as appropriate responses are assured, for, especially the managerial related questions. The distribution for the number of years in the IT role is also balanced as about $75.2 \%$ of the respondents fall between 0-9 years and the remaining, beyond 10 years. Again, this helps in the responses, as all the respondents have requisite IT knowledge to understand the subject matter.

\subsection{Descriptive Statistics of the Initial Dichotomous Questions}

Looking at the output, about $96 \%$ of the respondents responded in the affirmative that their organizations have recognized IT departments. The measures of central tendency (mean, mode and median) all converge at 1 or point to one (YES=1, NO=2 in SPSS), and so we can confidently conclude that all the Telcos under consideration in this research work have recognized IT departments. This is good news, as IT is seen as an integral part of the operations of the Telcos and not just a support function. To add to this success story, about $86.1 \%$ of the respondents also said that their organizations have a project management office (PMO) in place purposely for delivering IT projects. This means that for all the Telcos, there is a centralized unit for delivering projects of the business as against pockets of project offices scattered in the organization in the various departments. PMO ensures accountability and properly tracking of projects as against the common feature of corruption with the other one. IT projects are different in many respects from other forms of projects, and so it is good to know that for the Telcos in Ghana, there are dedicated IT project managers and IT program managers purposely for delivering IT projects. This is evidenced by the fact that about $83 \%$ and $84 \%$ of the respondents responded in the affirmative that IT program managers and IT project managers respectively are purposely assigned for delivering IT projects. When it came to justifying IT projects before they are delivered, about $95 \%$ of them responded in the affirmative. This means that for the Telcos in Ghana, IT projects are not just done, but that anticipated benefits are determined beforehand to establish their economic viability, as well as intangible benefits, and so on before they are delivered. Again, the results show that the Telcos are doing things right in terms of methodology. About $89.3 \%$ of the respondents said their organizations employ standard methodology to deploy IT projects. Without further analysis, we can confidently place the Telcos in Ghana between levels 3 to 5 of the capability maturity model (CMM). On reliance on external IT expertise to deliver IT projects, about $77 \%$ of the respondents said their companies rely on external IT expertise to deliver IT projects. This is the downside for the Telcos, as it is obvious or clear that the Telcos lack the requisite expertise when it comes to IT project delivery. This shows that the IT projects are delivered all right, but much of the salient work is done by outside expertise. It was also revealed from the results or output that there is a coordinated way of generating IT projects against ad-hoc means. $80 \%$ of the respondents affirmed that. This means that projects are not done anyhow but follow a rigorous process of selection before they are done. This ensures that IT projects are aligned with the organization's objectives and goals to ensure optimal benefits. The respondents also established the fact that their organizations can measure both tangible benefits ( $89 \%$ alluded to that fact), and intangible benefits ( $81 \%$ alluded to that fact). This is a good development, especially the intangible benefits because it is widely known that intangible benefits are difficult to measure; and this will help IT, managers, to push for more IT projects when the need arises.

\subsection{Analysis of the IT Benefits (BITI) Questions}

Table 1 below shows a summary of the output of the respondents of the benefits of IT investments. 
Table 1: BITI output summary

\begin{tabular}{|l|c|c|c|}
\hline \multicolumn{1}{|c|}{ QUESTION } & $\begin{array}{c}\text { \% (STRONGLY } \\
\text { AGREE + AGREE) }\end{array}$ & $\begin{array}{c}\text { \% (DISAGREE + } \\
\text { STRONGLY } \\
\text { DISAGREE) }\end{array}$ \\
\hline $\begin{array}{l}\text { IT investments/projects } \\
\text { bring about increased } \\
\text { revenue overtime }\end{array}$ & 93.4 & 5 & 1.6 \\
\hline $\begin{array}{l}\text { IT investments/projects } \\
\text { bring about enhanced } \\
\text { competitive advantage } \\
\text { overtime }\end{array}$ & 96.7 & 1.7 & \\
\hline $\begin{array}{l}\text { IT investments bring } \\
\text { about improved staff } \\
\text { morale overtime }\end{array}$ & 87.6 & 9.9 & \\
\hline $\begin{array}{l}\text { IT investments bring } \\
\text { about improved business } \\
\text { processes overtime }\end{array}$ & & & \\
\hline $\begin{array}{l}\text { IT investments bring } \\
\text { about improved decision- } \\
\text { making overtime }\end{array}$ & 94.2 & 5 & 0.8 \\
\hline $\begin{array}{l}\text { IT investments bring } \\
\text { about improved } \\
\text { product/service quality } \\
\text { overtime }\end{array}$ & 92.5 & 6.7 & 0.8 \\
\hline
\end{tabular}

From Table 1 above, it is clear that at least $85 \%$ of all the respondents agree that IT investments result in increased revenue, enhanced competitive advantage, improved staff morale, improved business processes, improved decision making, and improved product/service quality over time. The benefit "staff morale" recorded the least percentage of respondents $(87.6 \%)$ in the six benefits employed in this work.

Enhanced competitive advantage and improved product/service quality overtime recorded the highest $(96.7 \%)$. This implies that the respondents see IT investments as having more impact on these two benefits than the others. The results in the table also show that the respondents are so sure of the positive benefits of IT investments. The percentages of the respondents who disagreed are so small that they cannot be used to make any case to the effect that IT investments do not yield benefits for organizations.

\subsection{Ordinal Regression}

Employing ordinal regression using SPSS PLUM analysis comes with several assumptions that must be considered. First, the dependent variable should be measured at the ordinal level. Examples of ordinal variables include Likert items (e.g., a 5-point scale from "strongly agree" through to "strongly disagree". In our case, this assumption is satisfied, as the dependent variables, BITI1 to BITI6 are all fashioned in the 5-point Likert-scale. Secondly, the independent variables must be continuous, ordinal, or categorical (including dichotomous variables). However, ordinal independent variables must be treated as being either continuous or categorical. They cannot be treated as ordinal variables when running an ordinal logistic regression in SPSS Statistics. In SPSS, Ordinal or Categorical independent variables are treated as factors and continuous independent variables are treated as covariates. In this example, there are no continuous independent variables; we only have factors that are either ordinal or categorical. There are 14 independent variables (OIDT, OIBM, OIOC, OIAD, MIMS, MIIM, MITC, MITP, MIMC, SIIT, SIIE, SISD, SILR, SITS). Other assumptions come to play while running the PLUM (Polytomous Universal Model) procedure. A typical one has to do with the 
type of link function to use. To choose a link function, it is helpful to examine the distribution of values for the outcome or dependent variable. This can be achieved by running a histogram for say BITI1. The decision as to the type of link function to use will depend on the distribution of the outcomes of the various categories in the variable. The link function is a transformation of the cumulative probabilities of the dependent ordered variable that allows for the estimation of the model.

In SPSS, five-link functions are available, these link functions are as follows:

1. Logit function: Logit function is the default function in SPSS for ordinal regression. This function is usually used when the dependent ordinal variable has equal category. Mathematically, logit function equals to $f(x)=\log (x /(1-x))$.

2. Probit model: This is the inverse standard normal cumulative distribution function. This function is more suitable when a dependent variable is normally distributed.

3. Negative $\log -\log f(x)=-\log (-\log (x))$ : This link function is recommended when the probability of the lower category is high.

4. Complementary $\log -\log f(x)=\log (-\log (1-x))$ : This function is inverse of the negative $\log -\log$ function, it is recommended when the probability of higher category is high.

5. Cauchit. $\mathrm{F}(\mathrm{x})=\tan (\mathrm{p}(\mathrm{x}-0.5))$ : This link function is used when the extreme values are present in the data.

Logit and Probit are most used in ordinal regression, in most cases, a model is fitted with both functions, and the function with the better fit is chosen. However, probit assumes a normal distribution of the probability of the categories of the dependent variable when logit assumes the $\log$ distribution. Thus, the difference between logit and probit is typically seen in small samples.

Another important assumption as far as ordinal regression is concerned is the test for parallel lines. This assumption says that when you fit an ordinal regression you assume that the relationships between the independent variables and the logits are the same for all the logits. That means that the results are a set of parallel lines or planes - one for each category of the outcome variable. Parallel lines have the same slope, and so in effect, we are saying that all the logits have the same slope (the effect of the independent variable is the same for different logit functions).

The dependent variables (Benefits of IT investment) used or under consideration here are defined as follows: BITI1 (Increased Revenue), BITI2 (Enhanced Competitive Advantage), BITI3 (Improved Staff Morale), BITI4 (Improved Business Processes), BITI5 (Improved Decision Making), and BITI6 (Improved product/service quality).

The independent variables which are all defined as factors in SPSS and also represent complementary assets, are as follows: OIDP (strong information system development team), OIBM (efficient business processes and appropriate model), OIOC (supportive organizational culture that values efficiency and effectiveness), OIAD (decentralized authority and distributed decision making rights), MIMS (strong senior management support for technology investments and change), MIIM (incentives for management and innovation), MITC (teamwork and collaborative environments), MITP (training programs to enhance management decision skills), MIMC (management culture that values flexibility and knowledge-based decision making), SIIT (internet and telecommunications infrastructure), SIIE (IT-enriched educational programs raising labor force computer literacy), SISD (standards-government and private sector), SILR (laws and regulation creating fair, stable market environments), and SITS (technology and service firms in adjacent markets to assist in implementation). OIDP, OIBM, OIOC, and OIAD represent complementary assets resulting from organizational investments (OI), MIMS, MIIM, 
MITC, MITP, and MIMC represent complementary assets resulting from managerial investments (MI), and SIIE, SISD, SILR, and SITS represent complementary assets resulting from social investments (SI). The independent variables outlined above are 14 in number, and so the main aim is to run the PLUM procedure for each dependent variable (6 in all) against the 14 independent variables. The purpose, as has been established already in chapter one, is to analyze the relationships between the above-mentioned complementary assets and the benefits of IT investments.

\subsection{Reliability Testing}

Before questionnaires were sent out and administered, overall reliability testing was conducted on the independent variables. Cronbach's alpha method was used for the test. The result of 0.7 and above implied an acceptable level of internal reliability. Nunnally [108] had indicated 0.7 to be an acceptable reliability coefficient. Table 2 below shows the SPSS reliability testing output.

Table 2: Overall reliability testing output

\begin{tabular}{|l|l|}
\hline $\begin{array}{l}\text { Cronbach's } \\
\text { Alpha }\end{array}$ & No. of Items \\
\hline .808 & 14 \\
\hline
\end{tabular}

Referencing Table 2, it can be said that the overall Cronbach's alpha for the independent variables was above the threshold (0.7), indicating acceptable levels of internal reliability. Thus, question items defined were well related and aggregated to give a common view about the subject matter.

\subsection{PLUM Analysis}

To determine the type of link function to use, we analyze the histogram output of BITI1 to BITI6 from SPSS. The decision as to the type of link function to use will depend on the distribution of the outcomes of the various categories in the variable. Studying the outputs of the distributions of BITI1 to BITI6, the Logit function to use for the PLUM procedure shuffles between the negative log-log function and the Probit function since the response distributions in one breath looks like one with higher probabilities of a lower category and in other breath looks like a normal distribution. We, therefore, run PLUM for each dependent variable using these two link functions and choose the one with a better fit. The 5-point Likert-scale used in this research work is from 1 as strongly agree to 5 as strongly disagree. The lower categories are 1 and 2, and the higher categories, 4 and 5.

Appendix A, Table A1 shows the summary of the PLUM output with BITI1 to BITI6 as dependent variables and the 14 independent variables: OIDT, OIBM, OIOC, OIAD, MIMS, MIIM, MITC, MITP, MIMC, SIIT, SIIE, SISD, SILR, and SITS. Each of the dependent variables is run with the 14 independent variables separately, so in all, we have 6 PLUM outputs.

From Appendix A, Table A1, with BITI1 as the dependent variable, even though there was a good fit with Pearson statistic $(\mathrm{P}=0.137)$ and Deviance statistic $(\mathrm{p}=1)$, we realize that the model fitting information $(\mathrm{p}=0.277>0.05)$ makes the whole model not appropriate for predictors (independent variables) to have any significant impact on the response variable BITI1. No wonder there were no significant predictors recorded. This means that even though respondents believe that BITI1 (increased revenue) is a benefit resulting from IT investments, the results show that none of the complementary assets (independent variables) have a significant impact 
on it. It is only SITS (technology and service firms in adjacent markets to assist in implementation) which came close to significance with $\mathrm{p}=0.066$.

For BITI2 (Enhanced Competitive Advantage) as a dependent variable, the model fitting information has $\mathrm{p}=0.000$, which means predictors have a significant impact on BITI2, and this is true with three independent variables (OIAD, MIMC, and SITS) showing significance. With a positive estimate value of 4.109 for $\mathrm{MIMC}=3$, we say that as MIMC increases, so does the possibility/probability of being in one of the higher categories. OIAD $=1, \mathrm{OIAD}=2, \mathrm{OIAD}=3$, SITS $=1$, and SITS $=3$ are all related with BITI2 negatively, and hence as they $(\mathrm{OIAD}=1$, $\mathrm{OIAD}=2$, OIAD $=3, \mathrm{SITS}=1$, and $\mathrm{SITS}=3$ ) increase, the probability of being in one of the higher categories decrease or in other words, the probability of being in the lower categories increase. In summary, OIAD (decentralized authority and distributed decision-making rights), MIMC (management culture that values flexibility and knowledge-based decision making), and SITS (technology and service firms in adjacent markets to assist in implementation) have a significant impact on BITI2 (Enhanced Competitive Advantage).

For BITI3 (Improved Staff Morale) as a dependent variable, the model fitting information has $\mathrm{p}=0.000$, which means predictors have a significant impact on BITI3, and this is true with five independent variables (MITP, MIMC, SIIE, SILR, and SITS) showing significance. Except for SITS $=1$ with a negative estimate value of -1.841 , the rest $(\mathrm{MITP}=1, \mathrm{MITP}=2, \mathrm{MITP}=3$, $\mathrm{MIMC}=4$, SIIE $=1$, SIIE $=2$, SIIE $=3$, SIIE $=4$, and $\mathrm{SILR}=1$ ) have positive estimate values, and this means that as they $(\mathrm{MITP}=1, \mathrm{MITP}=2, \mathrm{MITP}=3, \mathrm{MIMC}=4$, SIIE=1, SIIE=2, SIIE=3, SIIE=4, and SILR=1) increase, so does the possibility/probability of being in one of the higher categories. In summary, MITP (training programs to enhance management decision skills), MIMC (management culture that values flexibility and knowledge-based decision making), SIIE (IT-enriched educational programs raising labor force computer literacy), SILR (laws and regulation creating fair, stable market environments), and SITS (technology and service firms in adjacent markets to assist in implementation) have significant impact on BITI3 (Improved Staff Morale).

For BITI4 (Improved Business Processes), the goodness-of-fit is not certain as Pearson $=0.000$ and Deviance $=1$, but the model fitting information $p=0.000$ suggests that predictors have a significant impact on the response variable BITI4. This is evidenced by the output with four significant independent variables (MIMS, MIIM, MITP, and SITS). Except for MIIM=1 which is negatively related to BITI4, the rest (MIMS, MITP, and SITS) are all positively related to BITI4. In summary, MIMS (strong senior management support for technology investments and change), MIIM (incentives for management and innovation), MITP (training programs to enhance management decision skills), and SITS (technology and service firms in adjacent markets to assist in implementation) have significant impact on BITI4 (Improved Business Processes).

For BITI5 (Improved Decision Making) as a dependent variable, the model fitting information has $\mathrm{p}=0.000$, which means predictors have a significant impact on BITI5, and this is true with two independent variables (OIAD and SIIE) showing significance. OIAD has a negative estimate value of -3.004 and $\mathrm{SIIE}=1$, SIIE=2, and $\mathrm{SIIE}=3$ have positive estimates, and this means that as they ( $\mathrm{SIIE}=1, \mathrm{SIIE}=2$, and $\mathrm{SIIE}=3$ ) increase, so does the possibility/probability of being in one of the higher categories. In summary, OIAD (decentralized authority and distributed decision-making rights) and SIIE (IT-enriched educational programs raising labor force computer literacy) have a significant impact on BITI5 (Improved Decision Making).

For BITI6 (Improved product/service quality) as a dependent variable, the model fitting information has $\mathrm{p}=0.011$, which means predictors have a significant impact on BITI6, and this is true with three independent variables (OIOC, OIAD, and SIIE) showing significance. $\mathrm{OIAD}=2, \mathrm{SIIE}=1, \mathrm{SIIE}=2$, and $\mathrm{SIIE}=3$ have negative estimate values and the rest $(\mathrm{OIOC}=1$, 
International Journal of Managing Value and Supply Chains (IJMVSC) Vol. 11, No. 2, June 2020

$\mathrm{OIOC}=2, \mathrm{OIOC}=3$, and $\mathrm{OIOC}=4$ ) have positive estimate values, and this means that as $\mathrm{OIOC}=1, \mathrm{OIOC}=2, \mathrm{OIOC}=3$, and $\mathrm{OIOC}=4$ increase, so does the possibility/probability of being in one of the higher categories. In summary, OIOC (supportive organizational culture that values efficiency and effectiveness), OIAD (decentralized authority and distributed decisionmaking rights) and SIIE (IT-enriched educational programs raising labor force computer literacy) have a significant impact on BITI6 (Improved product/service quality).

\section{CONClusion}

\subsection{Conclusion from Regression Output}

From the findings of the study, and in answering the research objective 3, the framework below was developed. The name of the framework is IT-Complementary Assets Investments Benefits (ICAIB) framework. The ICAIB framework summarizes the study and points clearly to the complementary assets required to complement or aid IT investments to produce specific benefits, particularly in the telecommunications industry. The ICAIB framework is shown in figure 2 below:

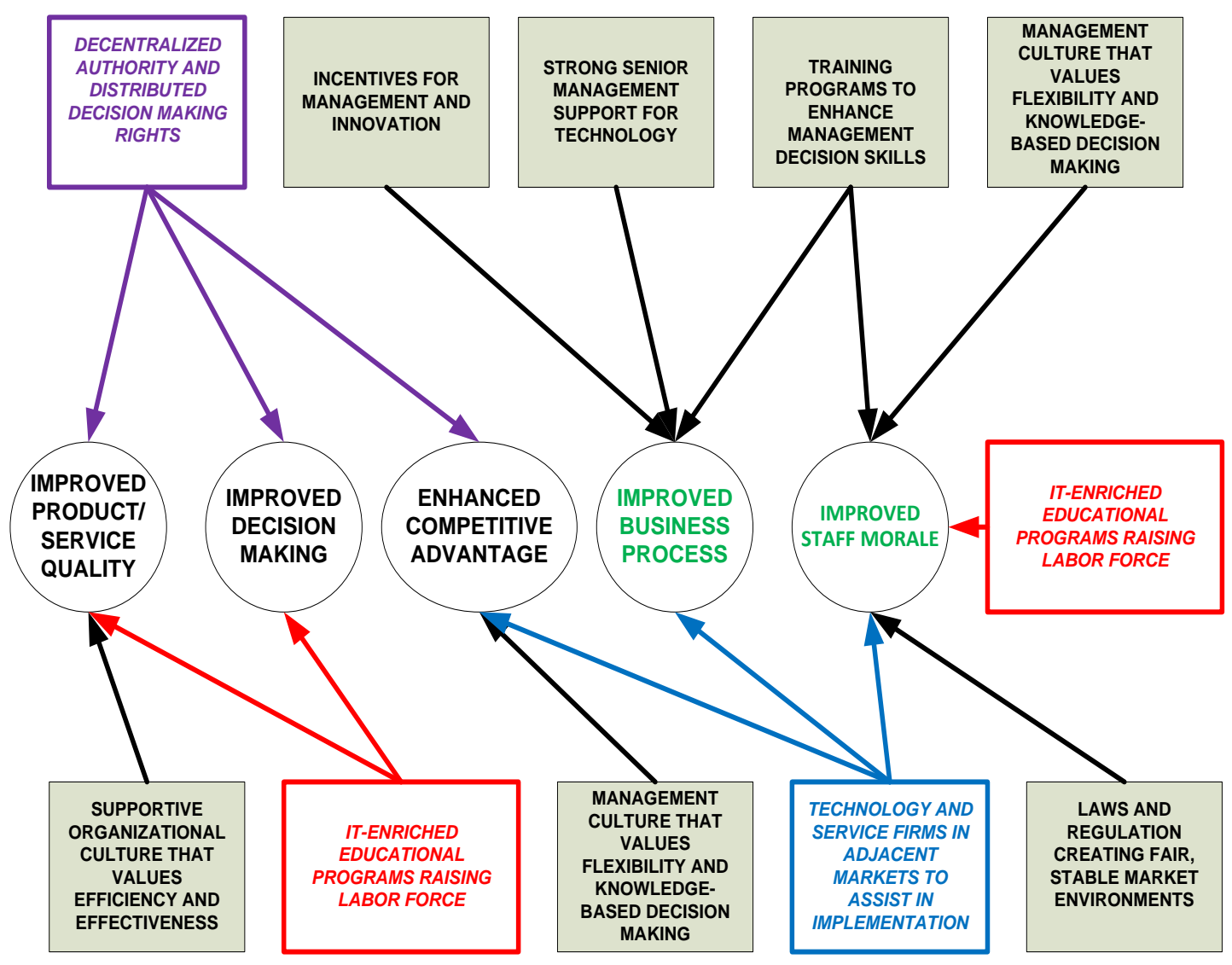

Figure 2: IT-Complementary Assets Investments Benefits (ICAIB) framework.

Note: Circle: Benefits of IT investments

Rectangle: Complementary Assets

Source: Author 
From the conceptual framework (see Figure 1), we realize that IT investments can take the form of office automation systems (OAS), transactional processing systems (TPS), management information systems (MIS), decision support systems (DSS), and Executive Support Systems (ESS). Again, these systems can be for strategic, support, or operational purposes, spanning from the top executive level to the ordinary person in the organization. The complementary assets are matched to the benefits based on the findings of the study. From Figure 2 above, we realize that among the six benefits of IT investments, only "increased revenue" did not appear (did not have any complementary asset leading or pointing to it). This means that increased revenue is not dependent on any of the 14 complementary assets employed in this study.

Enhanced competitive advantage as a benefit depends on three complementary assets: decentralized authority and distributed decision-making rights, Management culture that values flexibility and knowledge-based decision making, and Technology and service firms in adjacent markets to assist in implementation. Decentralized authority simply means reposing some level or form of authority in every staff to enhance efficiency, effectiveness, and reduce bureaucracy. Distributed decision-making rights foster innovation and again reduces bureaucracy. Management culture that values flexibility and knowledge-based decision making is a culture that is not rigid, but at the same time employs knowledge-based systems, where a store or a repository of expert knowledge with connections and linkages designed to facilitate its retrieval in response to specific queries, or to transfer expertise from one domain of knowledge to another, is incorporated. Technology and service firms in adjacent markets to assist in implementation has to do with the timely availability of firms to help in any form of implementation of IT investment delivery. The results of the research are saying that, with these complementary assets in place, IT investments will result in a competitive advantage for the organization.

The complementary assets "Training programs to enhance management decision skills", "Management culture that values flexibility and knowledge-based decision making", "ITenriched educational programs raising labor force computer literacy", "Laws and regulation creating fair, stable market environments", and "Technology and service firms in adjacent markets to assist in implementation" are necessary for IT investments to result in "improved staff morale" as a benefit or created value. This shows clearly that training is very essential to convert IT investments into improved staff morale as a benefit. From the diagram it is also realized that improved staff morale has the highest number of complementary assets pointing to it; five in all.

Incentives for management and innovation as a complementary asset is essential for improved business processes as a benefit of IT investments. This means that when innovation and good managerial acumen is rewarded, it can help in improving business processes beyond IT investments. Strong senior management support for technology investments and change as a complementary asset is also seen to help result in improved business processes beyond IT investments. Other complementary assets that help to result in improved business processes are training programs to enhance management decision skills, technology, and service firms in adjacent markets to assist in implementation.

Improved decision making as a benefit of IT investments depends on the decentralized authority and distributed decision-making rights and IT-enriched educational programs raising labor force computer literacy as complementary assets. This shows that IT investments alone cannot result in improved decision making and that these two complementary assets must be in place to achieve that.

With improved product/service quality as a benefit of IT investments, it was realized that supportive organizational culture that values efficiency and effectiveness, decentralized 
authority and distributed decision-making rights, and IT-enriched educational programs raising labor force computer literacy, are the complementary assets that point to it. This implies that for IT investments to produce improved product/service quality, effectiveness and efficiency organizational culture, computer literacy, and decentralized authority, and distributed decisionmaking rights are very essential as a base.

Complementary assets that pointed to most benefits (3 each) are "IT-enriched educational programs raising labor force computer literacy", "Technology and service firms in adjacent markets to assist in implementation", and "Decentralized authority and distributed decisionmaking rights". This establishes the fact that IT investments may not produce benefits expected in organizations if the staff are not computer literate or there are no programs in place to make them computer literate. IT investments are made for staff to make use of them to affect operations and management decisions and produce expected outcomes. If they do not have the requisite skills and knowledge to use these systems, the investments become a waste.

Again, IT investments may not produce the results or benefits expected if there are no technology and service firms or experts in adjacent markets to help in the implementation of the IT projects. Technology and service firms/experts in adjacent markets offer quick and ready solutions to help in the implementation of IT projects and problem resolution, to help organizations to always deliver seamlessly to achieve optimal results in terms of performance and value creation.

Also, IT investments may not produce the results or benefits expected if there is not in place decentralized authority and distributed decision-making rights. Decentralized decision-making is any process where the decision-making authority is distributed throughout a larger group. It also implies a higher authority given to lower-level functionaries, executives, and workers (https://en.wikipedia.org/wiki/Decentralized_decision-making). Professor Thomas W. Malone [33] explains that decentralization has three general benefits: encourages motivation and creativity, allows many minds to work simultaneously on the same problem, and accommodates flexibility and individualization. This means that with this complementary asset in place, employees are empowered, work burdens on top executives are relieved to allow them to think more strategically, emergencies are better prepared for, there is more efficient decision-making, and there is ease of expansion. This is a key complementary asset that helps to bring about value beyond IT investments.

\subsection{Managerial Implications}

The output of this study can be very beneficial to IT managers taking into consideration the following:

- Training of staff in IT, resulting in computer literacy results in improved business process overtime beyond IT investments

- Strong senior management support for technology investment and change results in improved staff morale overtime beyond IT investments

- Training programs to enhance management decision skills results in improved staff morale overtime beyond IT investments

- Management culture that values flexibility and knowledge-based decision-making results in improved staff morale overtime beyond IT investments

- Supportive organizational culture that values efficiency and effectiveness results in improved product/service quality overtime beyond IT investments

- Efficient business processes and appropriate model results in improved product/service quality overtime beyond IT investments 
- Efficient business processes and appropriate model result in increased revenue overtime beyond IT investments

- Incentives for management and innovation result in increased revenue overtime beyond IT investments

\subsection{Contribution to knowledge}

The research topic was finalized after reviewing several research articles/outputs in this area. A research gap of relationships between complementary assets and benefits of IT investments was identified. What is prevalent in literature has to do with the need for complementary assets to help realize benefits from IT investments, but the actual relationships of complementary assets with benefits of IT investments were missing. Theoretically, therefore, this research work fills that gap by showing relationships of specific complementary assets with specific benefits of IT investments.

Methodologically, this work contributes to knowledge in that the metrics used for the measurement of complementary assets in the questionnaire administration were not picked from literature but were developed after a focus group interview with IT project and program managers. This is therefore an addition to the literature for which future researchers can rely on for their research in this particular area.

Practically, the outcome of this work proposes several ways that IT managers can employ to ensure the benefits of IT investments. With this work, IT managers do not just assume that complementary assets are necessary for ensuring the benefits of IT investments, but that there is an objective proof to that effect.

The conceptual, theoretical, and the IT-Complementary Assets Investments Benefits (ICAIB) frameworks developed in this work are unique and are analytical tools that can be employed by IT managers and researchers, in general, to help resolve business problems, as well as advance research in this particular area.

\section{REFERENCES}

[1] Lin Â, B-W. Information technology capability and value creation: Evidence from the US banking industry. Technology in Society, ScienceDirect, Elsevier. 2007, 29, 93-106.

[2] Barua, A.; Kriebel, C. H.; Mulhopadhyay, T. Information Technologies and Business Value: An Analytic and Empirical Investigation. Information Systems Research. 1995, 6(1), pp.3-23.

[3] Brynjolfsson, E.; Hitt, L. Paradox lost? Firm-level Evidence on the Return to Information Systems.Management Science. 1996, 42(4), pp.541-558.

[4] Kaplan, D.; Krishnanm, R.; Padman, R.; Peters, J. Assessing Data Quality in Accounting Information Systems. Communications of the ACM. 1998, 41(2).

[5] Lehr, W.; Lichtenberg, F. Computer Use and Productivity Growth in U.S. Federal Government Agencies, 1987-92. Journal of Industrial Economics. 1998, 46(2), pp.257-279.

[6] Mahmood, M.A.; Mann, G. J. Measuring the Organizational Impact of information technology investment: an Exploratory Study. Journal of Management Information Systems. 1993, 10(1), pp.97-122.

[7] Rai, A.; Patnayakuni, R.; Patnayakuni, N. Technology investment, and Business Performance. Communications of the ACM. 1997, 40(7), pp.89-97.

[8] Berndt E.R.; Morrison, C. J. High-tech Capital formation and Economic Performance in U.S. Manufacturing Industries; An Exploratory Analysis. Journal of Econometrics. 1995, 65(1), pp.9-43.

[9] Koski, H. The implications of network use production network externalities and public networking programs for firm's productivity. Research Policy. 1999. 28(4), PP. 423-439.

[10] Strassman, P.A. Information Payoff: The Transformation of Work in the Electronic Age. Free Press, New York. 1985. 
International Journal of Managing Value and Supply Chains (IJMVSC) Vol. 11, No. 2, June 2020

[11] Strassman, P. A. The Business Value of Computers. New Cannan, CT:Information Economics Press. 1990.

[12] Brynjolfsson, E. The Productivity Paradox of Information Technology. Communications of the ACM.1993, 36(12), pp.67-77.

[13] Sircar, S.; Turnbow, J. L.; Bordoloi, B. A Framework for Assessing the Relationship between Information Technology Investments and Firm Performance. Journal of Management Information systems. 2000, 16(4), pp.69-97.

[14] YiHua, P. S.; Mykytyn, P. P. Information technology investment and firm performance: a perspective of data quality. Proceedings of the Seventh International Conference on Information Quality (ICIQ-02). 2002.

[15] Koi-Akrofi, G.Y.; Koi-Akrofi, J. Information Technology investments and organizational performance of the telecommunications industry in Ghana. Maxwell Scientific Organization. Research Journal of Information Technology. 2011, 3(3): 118-132.

[16] Teece, D. Economic Performance and Theory of the Firm: The Selected Papers of David Teece. London: Edward Elgar Publishing. 1998.

[17] Laudon, K.C.; Laudon, J.P. Management information systems: organization and technology in the networked enterprise. New Jersey: Prentice-Hall. 2012.

[18] Brynjolfsson, E. VII Pillars of IT Productivity. Optimize. 2003.

[19] Brynjolfsson, E.; Hitt, L. M. Beyond computation: Information technology, organization transformation, and business performance. Journal of Economic Prospects. 2000, 14, 4, 23-48.

[20] Davern, M. J.; Kauffman, R. J. Discovering potential and realizing value from information technology investments. Journal of Management Information Systems. 2000, 16(4), pp. 121-143.

[21] Laudon, K. C. Computers and Bureaucratic Reform. New York: Wiley. 1974.

[22] Ahmad, F.; Arshad, N. H. Value Delivery of Information Technology Investment: A Conceptual Framework. International Journal of Computer Theory and Engineering. 2014, Vol. 6, No. 2, PP. 150-154.

[23] Liang, T-P.; You, J-J.; Liu, C-C. A resource-based perspective on information technology and firm performance: a meta-analysis. Industrial Management \& Data Systems, Emerald Group Publishing Limited. 2010, Vol. 110 No. 8, pp. 1138-1158

[24] Dehning, B.; Richardson, V. J. Returns on Investments in Information Technology: A Research Synthesis. Journal of Information Systems. 2002, Vol. 16, No. 1, pp. 7-30

[25] Teece, D. J. Profiting from technological innovation: Implications for integration, collaboration, licensing, and public policy. Res. Policy. 1986, 15 285-305.

[26] Brynjolfsson, E.; Hitt, L. M. Beyond Computation: Information Technology, Organizational Transformation, and Business Performance. Journal of Economic Perspectives. 2000, 14, no. 4.

[27] Shank, G. Qualitative Research. A Personal Skills Approach. New Jersey: Merril Prentice Hall. 2002.

[28] Blaikie, N. Analysing Quantitative Data. London: Sage Publications 2003. 2003.

[29] Cohen. L.; Manion, L.; \& Morrison, K. Research Methods in Education. 5th edn. London: RoutledgeFalmer 2000. 2000.

[30] Kuzon, WM. Jr.; Urbanchek, MG.; McCabe, S. The seven deadly sins of statistical analysis. Ann Plastic Surg. 1996, 37:265-72.

[31] Motulsky, H. Intuitive Biostatistics- Chapter 37(ISBN 0-19-508607-4). Copyright (c) 1995 by Oxford University Press Inc. 1995.

[32] Gelman, A.; Hill, J. Data analysis using regression and multilevel/hierarchical models. New York: Cambridge University Press. 2007.

[33] Malone, Thomas W. Is 'Empowerment' Just a Fad? Control, Decision-Making, and Information Technology. Sloan Management Review 23. 1997, 38, no. 2.

\section{APPENDIX A}

Summary of PLUM output in Table A1 below: 
International Journal of Managing Value and Supply Chains (IJMVSC) Vol. 11, No. 2, June 2020

Table A1:Summary of PLUM output

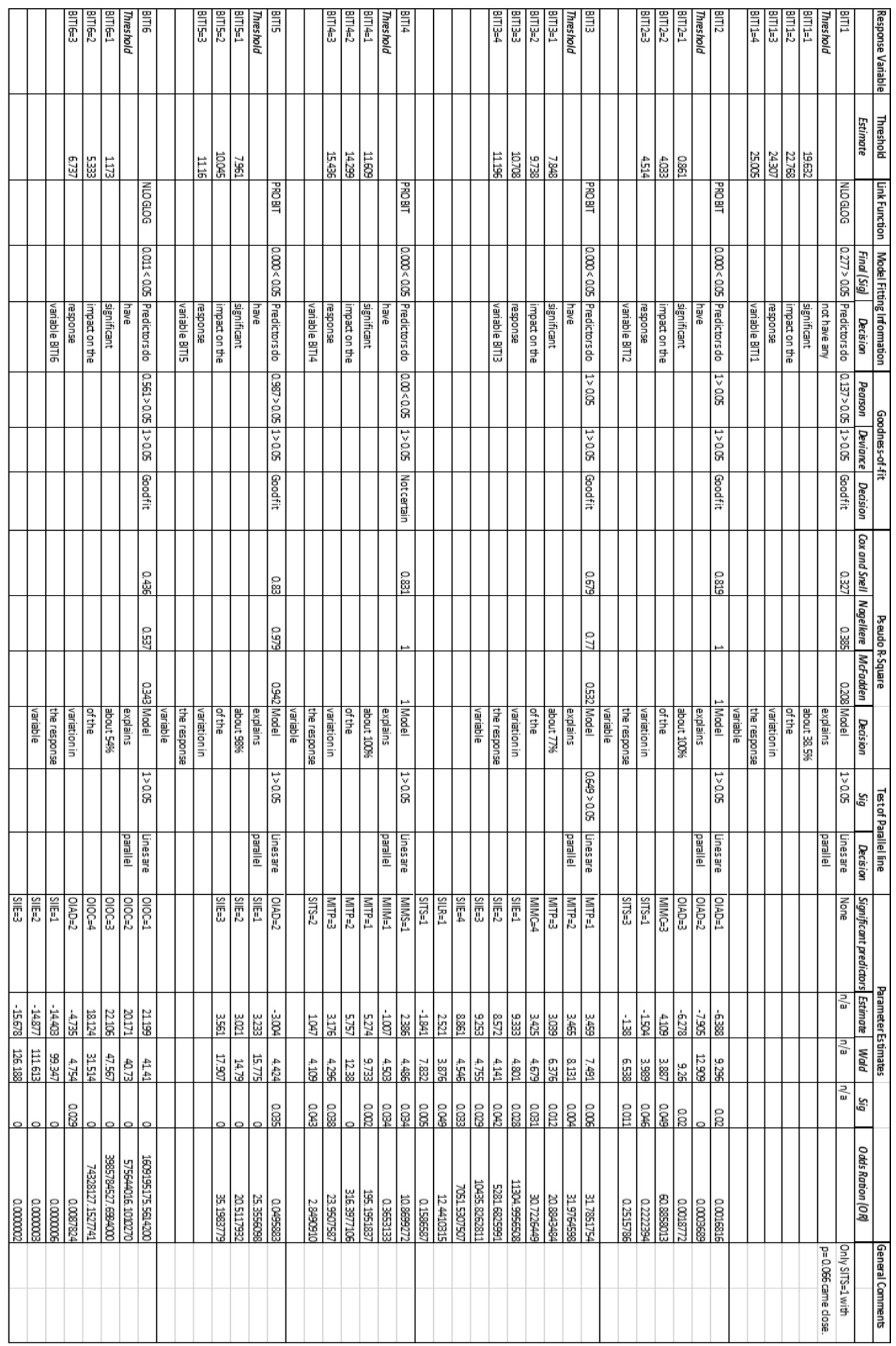




\section{APPENDIX B}

\section{Questionnaire}

\section{SURVEY QUESTIONS}

I would be very grateful if you could spare some of your quality time to fill this questionnaire for me to aid me in my research work, with the topic "COMPLEMENTARY ASSETS AND VALUE CREATION BEYOND IT INVESTMENTS".

\section{A. PERSONAL AND COMPANY INFORMATION}

i. Name of organization:

ii. Position in the organization:

iii. Number of years working in the organization: A. $0-4$ B. $5-9$ C. $10-14$ D. ABOVE

14

iv. Number of years in management role: A. $0-4 \quad$ B. $5-9 \quad$ C. 10-14 $\quad$ D. ABOVE 14

$\begin{array}{llll}\text { v. Number of years in IT role: A. 0-4 } & \text { B. 5-9 } & \text { C. 10-14 } & \text { D. ABOVE } 14\end{array}$

vi. Does your organization have a recognized IT department? A. YES B. NO

vii. Does your organization have a project management office (PMO) responsible for delivering IT projects? A. YES B. NO

viii. Does your organization have a program manager purposely for IT projects? A. YES B. NO

ix. Does your organization has dedicated IT project managers for delivering IT projects?

A. YES B. NO

x. Does your organization justify every IT project before it is delivered? A. YES B. NO

xi. Does your organization have a standard methodology for delivering IT projects? A. YES B. NO

xii. Does your organization rely on external IT expertise to deliver IT projects? A. YES B. NO

xiii. Does your organization have a coordinated way of generating IT projects against ad hoc means? A. YES B. NO

xiv. Does your organization have the capacity to measure tangible benefits (benefits that are easy to quantify or measure.E.g. accounting/financial measures such as Return on InvestmentROI, Net Present Value-NPV, etc.)of IT investments? A. YES B. NO

xv. Does your organization have the capacity to measure intangible benefits (benefits that are difficult to measure or quantify. E.g. enhanced competitive advantage, improved business process, etc.)of IT investments? A. YES B. NO

\section{B. Main Questions}

\section{BENEFITS OF IT INVESTMENTS (BITI)}

A. IT investments/projects bring about increased revenue overtime. This is seen or realized from the increased sales figures resulting from investments in IT
1. Strongly Agree
2. Agree
3. Neutral
4. Disagree
5. Strongly Disagree

B. IT investments/projects bring about enhanced competitive advantage overtime. This is seen in how the company leverages IT to produce superior products/services that are different from competitors and at a competitive price.
1. Strongly Agree
2. Agree
3. Neutral
4. Disagree
5. Strongly Disagree 
International Journal of Managing Value and Supply Chains (IJMVSC) Vol. 11, No. 2, June 2020

C. IT investments/projects bring about improved staff morale overtime. This is seen in how IT helps staff in their daily duties/activities to meet their targets on time and improve their performance.
1. Strongly Agree
2. Agree
3. Neutral
4. Disagree
5. Strongly Disagree

D. IT investments/projects result in improved business processes overtime. This is seen in how processes are automated and computerized.
1. Strongly Agree
2. Agree
3. Neutral
4. Disagree
5. Strongly Disagree

E. IT investments/projects result in improved decision-making overtime. This is seen in the use of computer technology to help in decision-making processes.

1. Strongly Agree 2. Agree 3. Neutral 4. Disagree 5. Strongly Disagree

F. IT investments/projects bring about improved product/service quality overtime. This is seen in how IT helps to improve products/services periodically to the satisfaction of customers.
1. Strongly Agree
2. Agree
3. Neutral
4. Disagree
5. Strongly Disagree

\section{ORGANIZATIONAL INVESTMENT(OI)}

\section{A. Strong Information System development team}

1. Success rates of System Integration Test (SIT) and User Acceptance Test (UAT) are between $80 \%$ and $100 \%$

2. Success rates of SIT and UAT are between $60 \%$ and $80 \%$

3. Success rates of SIT and UAT are between $40 \%$ and $60 \%$

4. Success rates of SIT and UAT are between $20 \%$ and $40 \%$

5. Success rates of SIT and UAT are between $0 \%$ and $20 \%$

B. Efficient business processes and appropriate model

Rate the speed of delivery of products and services, customer feedback and internal customer complaints

1. High speed of delivery of products and services, excellent customer feedback and minimal internal customer complaints

2. Normal speed of delivery of products and services, good customer feedback and normal internal customer complaints

3. Low speed of delivery of products and services, poor customer feedback and excessive internal customer complaints

C. Supportive organizational culture that values efficiency and effectiveness

Rate the awareness of the staff concerning the processes and products of the company

1. Excellent

2. Very good

3. Good

4. Average

5. Poor

D. Decentralized authority and distributed decision-making rights

1. Decision making is very fast

2. Decision making is fast

3. Decision making is slow

4. Decision making is very slow 


\section{MANAGERIAL INVESTMENTS(MI)}

\section{A. Strong senior management support for technology investments and change}

1. High level of Funding plus ample materials and human resources are provided for IT projects, and so above $80 \%$ of all planned IT projects are executed

2. Appreciable level of Funding plus adequate materials and human resources are provided for IT projects, and so between $50 \%$ to $80 \%$ of all planned IT projects are executed

3. Insignificant level of Funding plus inadequate materials and human resources are provided for IT projects, and so below 50\% of all planned IT projects are executed

\section{B. Incentives for management and innovation}

1. There is a reward scheme in place to reward innovation and managerial acumen

2. There is no reward scheme in place to reward innovation and managerial acumen

\section{Teamwork and collaborative environments}

The rate in terms of the success of IT projects: delivered on time, of high quality, according to specifications, and with fewer changes:

1. Very successful (all four conditions met)

2. Successful (three conditions met)

3. Less successful (two conditions met)

4. Failure (1 or no condition met)

\section{Training programs to enhance management decision skills}

Management organizes frequent, high-quality training programs that enhance management decision skills:

1. Strongly agree

2. Agree

3. Neutral

4. Disagree

5. Strongly disagree

E. Management culture that values flexibility and knowledge-based decision making Rate the level of motivation and innovation of staff:

1. Very High

2. High

3. Normal

4. Low

5. Very Low

\section{SOCIAL INVESTMENTS(SI)}

\section{A. Internet and Telecommunications infrastructure}

1. Staff have access to the internet and IT infrastructure 24 hours

2. Staff have access to the internet and IT infrastructure less than 24 hours

\section{B. IT-enriched educational programs raising labor force computer literacy}

1. More than $80 \%$ of staff can resolve first-line maintenance issues

2. Between $60 \%$ and $80 \%$ of staff can resolve first-line maintenance issues

3. Between $40 \%$ and $60 \%$ of staff can resolve first-line maintenance issues

4. Between $20 \%$ and $40 \%$ of staff can resolve first-line maintenance issues

5. Between $0 \%$ and $20 \%$ of staff can resolve first-line maintenance issues 
International Journal of Managing Value and Supply Chains (IJMVSC) Vol. 11, No. 2, June 2020

C. Standards (Government and private sector): E.g. Bank of Ghana for banking products and telecom products (e.g. mobile money), Standard board for all telecom and IT equipment, products, etc.

1. No issues with government agencies responsible for standards (products, services, operations, etc.)

2. Few issues with government agencies responsible for standards (products, services, operations, etc.)

3. More issues with government agencies responsible for standards (products, services, operations, etc.)

D. Laws and regulation creating fair, stable market environments:

1. No surcharges or issues with the regulatory body

2. Surcharges and few issues with the regulatory body

3. Surcharges and more issues with the regulatory body

\section{E. Technology and service firms in adjacent markets to assist in implementation}

1. Vendors, manufacturers, and suppliers are always difficult to get for an engagement

2. Vendors, manufacturers, and suppliers are sometimes difficult to get for an engagement

3. Vendors, manufacturers, and suppliers are always easy to get for an engagement

4. Vendors, manufacturers, and suppliers are sometimes easy to get for an engagement

Thank You.

\section{AUTHOR}

Godfred Yaw Koi-Akrofi is a senior lecturer and HOD for the Information Technology Studies Department of the University of Professional Studies, Accra in Ghana. He has a Ph.D. in Management- Information Systems Management (ISM) from Universidad Central de Nicaragua (UCN), MBA in Management Information Systems (MIS) from University of Ghana Business School (UGBS), University of Ghana, Accra, Ghana, and Bachelor of Science (B.Sc.) in Electrical/Electronic Engineering, Kwame Nkrumah University of Science and Technology (KNUST), Kumasi, Ghana. He has worked with multinationals such as British Telecom, AT \& T, MCI Communications Corp., Sprint Corporation, Verizon Communications, Deutsche Telekom, KPN, Orange, Telenor ASA, and so on as a Telecom engineer/Manager and Interconnect (Technical, Sales and Accounting) Manager with Ghana Telecom/Vodafone Ghana/Huawei Technologies for over 10 years. He has Twelve years of experience as a lecturer in Tertiary education. He has 18 peer-reviewed journal articles, three books, and three conference papers. Areas of Research are in IT/IS Management, Telecommunications, MIS and the organization, Organizational Behaviour, and Management, Business Organizational Dynamics, PostMerger/Acquisition Dynamics in the Telecoms and IT sectors, Quality Management, IS/IT/Business Strategy, IT/IS Project Management/ IT Design and Systems Thinking, IT investments and organizational performance, Complementary assets and value creation beyond IT investments. 